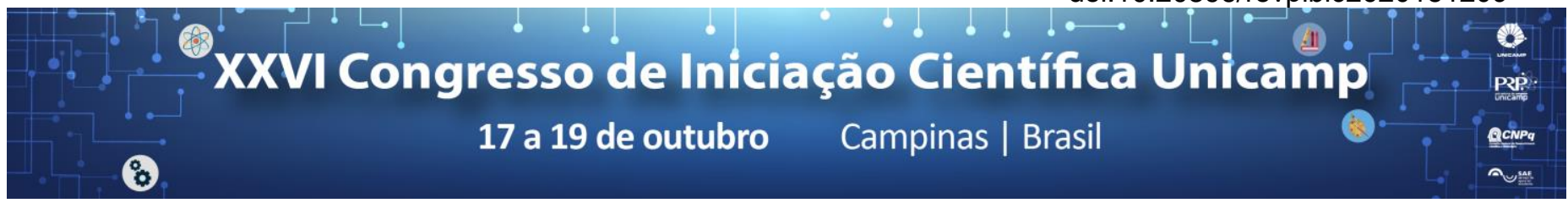

\title{
Avaliação do prurido e sua relação com a depressão, ansiedade, estresse pós-traumático e qualidade de vida em brasileiros vítimas de queimaduras
}

\section{Renata R. Bispo*, Roberta Cunha Matheus Rodrigues, Natália Gonçalves.}

\section{Resumo}

Este estudo tem como objetivo avaliar o prurido, a ansiedade, a depressão, o estresse pós-traumático e a qualidade de vida relacionada à saúde (QVRS) de vítimas de queimaduras entre dois meses e meio e quatro meses após o trauma. Método: pesquisa descritiva e transversal, com vítimas de queimaduras adultas. Foram utilizados instrumentos de caracterização sociodemográfica, clínica e avaliação de cada variável. Resultados e Discussão: foram entrevistados 60 pacientes, sendo a maioria homens (73\%), que se acidentaram no domicilio (52\%) queimando-se com a associação de álcool e fogo (33,3\%); Em relação às variáveis de interesse, a amostra apresentou escore médio de intensidade de prurido de 5 (DP: 2,7), escore médio de estresse pós-traumático de 54 (DP:39), ansiedade de 6,5 (DP: 4,5), depressão de 3,9 (DP: 3,9) e escore médio de QVRS de 8,2 (DP: 18,1). Foram constatadas correlações positivas significativas de moderada a forte magnitude entre o prurido e o IES $(r=0,43 ; P=0,001)$, ansiedade $(r=0,39 ; P=0,002)$, depressão $(r=0,53$; $P=0,0001)$, FLQA-wk $(r=0,58 ; P=0,0001)$

Palavras-chave: Prurido, queimaduras e qualidade de vida

\section{Introdução}

O prurido é um sintoma esperado em pacientes queimados, visto que, no processo cicatricial do tecido lesado, a liberação de mediadores bioquímicos irá estimular a percepção do sintoma pelo paciente ${ }^{1}$. Além disso, pode ser encontrado comprometimento psicológico nos pacientes, decorrente do evento traumático, distúrbios da autoimagem, autonomia e relações sociais prejudicada2. Esses fatores podem estar associados e alterar a QVRS das vítimas de queimaduras e aumentar o sintoma de prurido ${ }^{2}$

Assim este estudo tem como objetivo, avaliar o prurido, a ansiedade, a depressão, o estresse póstraumático e a QVRS, de vítimas de queimaduras entre dois meses e meio a quatro meses após o trauma, e correlacionar o prurido com as demais variáveis.

Trata-se de um estudo descritivo e transversal. A amostra foi composta por vítimas de queimadura, entre dois meses e meio e quatro meses após o acidente e maiores de idade. Foram excluídos da amostra pacientes com diagnósticos psiquiátricos e queimaduras provenientes da tentativa de autoextermínio. Os dados foram coletados por meio de um instrumento de caracterização sociodemográfica e clínica e das escalas: Ansiedade e Depressão Hospitalar (HADS), Impacto do Evento (IES), Escala Visual Numérica (EVN) para a avaliação da intensidade do prurido e Freiburg Life Quality Assessment Wound (FLQA-wk) para avaliar a QVRS. Este estudo foi aprovado pelo Comitê de Ética, sob CAAE: 59899716.8.0000.5404.

\section{Resultados e Discussão}

Dos 60 pacientes entrevistados, a maioria foi composta por homens que se acidentaram em casa por meio da associação de álcool e fogo (Tabela 1).

Tabela 1. Caracterização social e clínica.

\begin{tabular}{ll|ll}
\hline Variável & N (\%) & Variável & Média (DP) \\
\hline $\begin{array}{l}\text { Sexo } \\
\text { Masculino }\end{array}$ & $44(73)$ & $\begin{array}{l}\text { Superfície } \\
\text { queimada }\end{array}$ & $16,7(9,5)$ \\
\hline $\begin{array}{l}\text { Agente } \\
\text { Álcool+fogo }\end{array}$ & $20(33)$ & $\begin{array}{l}\text { Período } \\
\text { pós trauma }\end{array}$ & $3,1(0,43)$ \\
Fogo & $11(18)$ & $\begin{array}{l}\text { (meses) } \\
\end{array}$
\end{tabular}

Os dados foram submetidos à análise descritiva (Tabela 2) e de correlação (Coeficiente de correlação de Spearman). O nível de significância adotado é de 0,05. (Tabela 3).

Tabela 2. Caracterização das variáveis avaliadas $(\mathrm{N}=60)$

\begin{tabular}{lc}
\hline Instrumento & Média (DP) \\
\hline EVN & $5,0(2,7)$ \\
HAD-A & $6,5(4,5)$ \\
HAD-D & $3,9(3,9)$ \\
IES & $54(39)$ \\
FLQA-wk & $51(15,5)$ \\
\hline
\end{tabular}

Tabela 3. Coeficiente de correlação (r) entre o prurido e as demais variáveis $(\mathrm{N}=60)$

\begin{tabular}{lc}
\hline & EVN \\
& $\mathbf{r}(\mathbf{P})$ \\
\hline HAD-A & $0,39(0,002)$ \\
HAD-D & $0,53(0,0001)$ \\
IES & $0,43(0,001)$ \\
FLQA-wk & $0,63(0,0001)$ \\
\hline
\end{tabular}

$\mathrm{P}<0,05$ considerado estatisticamente significativo

\section{Conclusões}

Nesta amostra, os participantes apresentaram queimaduras moderadas, queixa de prurido de moderada intensidade, bom estado de saúde mental e boa QVRS. Todas as variáveis correlacionaram-se com o prurido, no entanto, com maior magnitude com a depressão e a QVRS.

\section{Agradecimentos}

Ao Conselho Nacional de Desenvolvimento Científico e Tecnológico pelo incentivo financeiro, às instituições de saúde Santa Casa de Campinas e Santa Casa de Limeira por permitir a realização da pesquisa.

\footnotetext{
1 1Finnerty, C.C.; Jeschke, M.G.; Branski, L.K.; et al. Hypertrophic scarring: the greatest unmet challenge after burn injury. Series. 2016; 388: 1427-1436

2 Dahal, O.; Wickman M.; Wengströ Y. Adapting to Life After Burn Injury. Reflections on Care. Journal of Burn Care \& Research. 2012; 33(5); 595-604.
} 